\title{
A PRODUÇÃO DA VOGAL ÁTONA FINAL /e/ EM PORTUGUÊSS BRASILEIRO (L1) E ESPANHOL (L2) - UM ESTUDO EXPLORATÓRIO
}

\author{
Bruna da Rosa de Los Santos \\ (UFRGS) \\ Ubiratã Kickhöfel Alves \\ (UFRGS/CNPq)
}

\section{RESUMO:}

Este artigo apresenta um experimento sobre a produção da vogal átona final /e/, por aprendizes sul-riograndenses de espanhol (L2). Procuramos testar o efeito das variáveis status cognato e tempo de estudo formal da L2 (Grupo A: três anos de estudo; Grupo B: entre quatro e seis anos de estudo). As produções das vogais finais das palavras-alvo, que se encontravam em frases-veículo, foram analisadas acusticamente. Os resultados encontrados mostraram um efeito de língua, o que indica que os aprendizes de espanhol fazem a distinção entre a vogal átona /e/ do português e a do espanhol, em termos de altura e anterioridade/posterioridade. Entretanto, não foi encontrado nenhum efeito quanto ao status cognato e quanto ao tempo de experiência na L2. Tais resultados despertam a discussão acerca do papel da variável referente ao status cognato nas produções orais de aprendizes com maior tempo de estudo da L2.

PALAVRAS-CHAVE: bilinguismo; espanhol (L2); status cognato; experiência com a L2; produção vocálica.

\section{1 lntrodução}

Partindo de uma concepção dinâmica de língua (DE BOT et al., 2013; BECKNER et al., 2009), consideramos que o desenvolvimento fonético-fonológico por parte do bilíngue é pautado pela interação entre os dois sistemas linguísticos, a Primeira Língua (L1) e a Segunda Língua (L2) ${ }^{1}$. Especificamente no âmbito da Fonética e Fonologia, modelos perceptuais teóricos (como o Speech Learning Model, de FLEGE, 1995, 
2003) e estudos experimentais (como o de KUPSKE, 2015; PEREYRON \& ALVES, 2016; PEREYRON, 2017) revelam achados que evidenciam essa interação entre as línguas de um bilíngue/trilíngue, principalmente quando a questão envolve desenvolvimento de sistemas vocálicos.

Considerando tais postulados, a motivação da presente pesquisa vem da observação de que na cidade de Rio Grande (RS, Brasil), assim como em outros dialetos do português brasileiro (PB), estudos sociolinguísticos apontam que a vogal final é produzida como alta praticamente de forma categórica (ex: entop [i], baqu[i], esnob[i], sangu[i]). Tal fato corresponde a um desafio a ser enfrentado por aprendizes de espanhol (L2). Ainda que o fenômeno também ocorra em algumas variedades isoladas do espanhol, como já foi evidenciado (LIPSKI, 2007; REAL ACADÉMIA ESPAÑOLA, 2011), o mesmo é estigmatizado em tal língua. Sendo assim, surgiu o questionamento sobre como essa vogal passa a ser produzida (em ambas as línguas) quando falantes nativos de PB, moradores de Rio Grande, estão aprendendo espanhol como L2 (Grupo A: três anos de estudo da L2; Grupo B: entre quatro e seis anos de estudo da L2), considerando-se, portanto, as particularidades de cada língua no que tange à realização da vogal átona final /e/ e à dinamicidade advinda do processo de desenvolvimento de uma L2.

Em vista disso, no presente artigo, apresentamos um experimento cujo objetivo principal era verificar se aprendizes de espanhol distinguiam em suas produções as vogais átonas finais /e/ do PB e do espanhol, especificamente no que diz respeito aos padrões acústicos da vogal analisada (altura/F1 e anterioridade-posterioridade/F2). A partir desta observação, propusemos testar se o status cognato e o tempo de experiência na L2 causariam efeitos na produção dessa vogal. Para a obtenção dos dados, realizamos a gravação de duas tarefas de leitura (de frases-veículo), uma realizada em português e outra realizada em espanhol. Foram realizadas análises acústicas de dados de fala, coletados com aprendizes de espanhol como Segunda Língua (L2).

Este trabalho se organiza da seguinte forma: primeiramente, será apresentado o referencial teórico que embasa o presente estudo. Logo, se detalha a metodologia aplicada, na qual constam todas as informações referentes às hipóteses testadas, aos participantes, aos materiais utilizados e aos procedimentos metodológicos. Após a metodologia, se apresentam as descrições e análises dos resultados. A última seção é dedicada às considerações finais. 


\section{Referencial teórico}

\section{1 língua como Sistema Adaptativo Complexo (Com- plex Adaptative System - CAS)}

Neste estudo, consideramos a língua como um Sistema Adaptativo Complexo (BECKNER et al., 2009), por enxergar a língua(gem) como um sistema aberto, influenciado por diversos fatores estruturais, ambientais, sociais e desenvolvimentais. Dessa forma, a língua passa, então, a compor outro tipo de estrutura organizativa caracterizada não apenas pela sistematicidade, mas também pela adaptação inerente e constante e pela natureza interativa e complexa.

Além disso, tomando como objeto de estudo dados de aprendizes de L2, a adaptação do espaço fonético-fonológico do sujeito é inevitável, considerando-se que as duas línguas coexistem neste mesmo espaço, conforme os postulados do Speech Learning Model (SLM - FLEGE, 1995, 2003).

A mudança ou movimento também é uma das características inerentes dos sistemas (ou subsistemas) da língua, porque "todos os (sub) sistemas complexos mudam continuamente, às vezes sutilmente, outras vezes de forma abrupta" (DE BOT et al., 2013). Essa mudança só é possível porque se considera a variável tempo, referente à trajetória desenvolvimental contínua do sujeito. A língua, portanto, está sempre em mudança e em desenvolvimento, à luz desta perspectiva.

\subsection{A vogal átona final /e/ no português brasileiro (PB) e no espanhol}

No que diz respeito a estudos de cunho variacionista, há uma vasta literatura sobre vogais no Brasil, principalmente na Região Sul. Grande parte dos trabalhos desenvolvidos nessa região se devem à sua significativa pluralidade linguística, visto o grande número de comunidades bilíngues (italianos e alemães, por exemplo).

De forma semelhante, a língua espanhola é também plural, visto que é falada em 21 países, abrangendo, portanto, elementos culturais e linguísticos específicos de cada comunidade sociolinguística na qual é produzida. Assim, há uma grande variação dialetal na língua espanhola. Contudo, apesar de tanta diversidade, o sistema vocálico do espanhol é considerado mais estável do que o sistema vocálico do português. Isto se 
deve ao fato de que tal sistema mantém, na maioria de seus dialetos, cinco vogais, ao contrário do $\mathrm{PB}$, que varia de sete a três vogais, a depender da posição silábica e da região brasileira.

O sistema vocálico do português brasileiro (PB) foi sistematizado por Câmara Jr. (1970), que estabelece a ocorrência das seguintes vogais: $i, e, \varepsilon, a, o, \jmath, u$ (em posição tônica), $u, o, a, e, i$ (em posição pretônica), $u, a, e, i$ (em posição postônica não-final) e $u, a, i$ (em posição postônica final). Dessa forma, na posição de interesse desta pesquisa, considerando o falar da cidade de Rio Grande (RS), haveria um sistema vocálico reduzido a três vogais.

Já o sistema vocálico do espanhol, segundo Conde (2001), é constituído por cinco vogais $i, e, a, o, u$, em qualquer posição silábica e na grande maioria dos dialetos, embora não sejam frequentes no léxico palavras terminadas em /i/ e /u/ (ALARCOS LLORACH, 1975; BRISOLARA \& SEMINO, 2015). Assim, tal sistema é mais compacto e mais "estável", se comparado ao sistema brasileiro.

Quanto ao fenômeno de produção das vogais átonas finais como altas, comum em variedades do $\mathrm{PB}$, o mesmo não é considerado característica do espanhol. A literatura sinaliza a ocorrência deste fenômeno (LIPSKI, 2007; REAL ACADEMIA ESPAÑOLA, 2011), mas em poucas variedades e por influências de línguas indígenas. Dado o contexto de tal fenômeno, o mesmo é muito estigmatizado e não consta nos materiais didáticos de espanhol como L2.

No que diz respeito à caracterização acústica do PB e do espanhol, é importante ressaltar a escassez de trabalhos acústicos detalhados sobre ambas as línguas, considerando-se a grande variação das mesmas e até mesmo as diferentes posições silábicas. Neste estudo, por lidarmos com produções vocálicas de gaúchos, contamos, como referência, com os valores acústicos de Matzenauer et al. (2015, /i/ F1 de 306 Hz e F2 de 2020 Hz; /e/ F1 de 320 Hz e F2 de 2018 Hz)² e Brisolara e Solé (2016, /e/ F1 de $414 \mathrm{~Hz}$ e F2 de $1681 \mathrm{~Hz})^{3}$, de Pelotas e Rio Grande, respectivamente. Já para as vogais do espanhol ${ }^{4}$, encontramos os trabalhos referentes às vogais de Montevidéu e Buenos Aires, de Aronson et al. (2000, /i/ F1 de $330 \mathrm{~Hz}$ e F2 de $2765 \mathrm{~Hz}$; /e/ F1 de $330 \mathrm{~Hz}$ e F2 de $2500 \mathrm{~Hz}$ ), Santos \& Rauber (2014, /i/ F1 de $321 \mathrm{~Hz}$ e F2 de 2647 Hz; /e/ F1 de 472 Hz e F2 de 2270 Hz) e Pereyron e Alves (2016, /i/ F1 de 343,6 Hz e F2 de 2105,8 Hz; /e/ F1 de 457,2 Hz e F2 de 1892,8 Hz) ${ }^{5}$. 


\subsection{Sobre o status cognato}

Apoiados nos postulados do Speech Learning Model (FLEGE, 1995, 2003) de que os dois sistemas vocálicos do bilíngue compartilham um mesmo espaço fonético-fonológico, consideramos que acesso lexical e desenvolvimento fonético-fonológico se interligam, na medida em que estes dois construtos "conversam" sobre a ativação consecutiva ou simultânea no cérebro bilíngue. É possível estabelecer uma relação direta entre o postulado de Flege (1995, 2003), anteriormente mencionado, com as propostas de acesso lexical: se os dois sistemas linguísticos, em termos de categorias fonético-fonológicas, compartilham o mesmo espaço, ao se realizar uma vogal, independentemente da língua utilizada no momento, os dois sistemas linguísticos podem ser ativados, paralelamente.

Uma das variáveis investigadas nas pesquisas de acesso lexical é o status cognato. De modo geral, Dijstra et al. (1998, p. 55) afirmam que tal efeito "pode ser atribuído a uma maior ativação das representações semânticas (parcialmente) compartilhadas em caso de cognatos", isto é, palavras cognatas podem facilitar o acesso lexical. Ortiz Preuss (2011) e Ortiz Preuss, Fontes e Finger (2015), investigando a 'interferência interlinguística' na lexicalização em L2, já apresentam resultados de efeito do status cognato na ativação e seleção lexical.

Além disso, segundo Ortiz Preuss, Fontes e Finger (2015), existe uma discussão teórica na literatura bilíngue que diz respeito ao percurso de ativação. Enquanto alguns pesquisadores defendem que a ativação conceitual é seguida pela ativação semântica e, por último, pela ativação fonológica, outros defendem uma bidirecionalidade, que, por sua vez, permite a retroalimentação entre o nível fonológico e o nível lexical.

Estudos como o de Ortiz Preuss, Fontes e Finger (2015), ao utilizarem uma tarefa de nomeação de figuras, conseguem prever efeitos de palavras distratoras, com proximidade fonológica da palavra-alvo, no acesso e seleção da palavra-alvo. Isso seria um indício de bidirecionalidade nos processos de acesso e seleção lexical. Considerando estes achados, o papel do status cognato é relevante, porque o tipo de palavra pode levar a diferentes influências neste tipo de processo cognitivo. Segundo a literatura, as cognatas, por exemplo, contribuem com uma maior facilitação semântica e fonológica (pela semelhança na grafia e/ou na pronúncia).

Não cabe no escopo deste artigo mencionar e discutir todas as pesquisas sobre acesso lexical, mas consideramos pertinente testar se, para 
além de processos cognitivos como o acesso e a seleção lexical, haveria efeito do status cognato nas produções das vogais finais, em português e em espanhol, dos aprendizes de espanhol como L2 com, no mínimo, 3 anos de experiência com estudos formais do idioma. Tal verificação se mostra pertinente para explorar efeitos de ativação interlinguística no que diz respeito, portanto, à produção específica de categorias fonético-fonológicas.

\section{Metodologia}

\subsection{Hipóteses}

H1: haverá distinção, em termos de padrões acústicos (F1 e F2), entre as produções da vogal átona final /e/ do português (L1) e sua contraparte no espanhol (L2).

Motivação: considera-se que essa é uma característica saliente da L2, quando comparada com a variante de L1 desses aprendizes (em que a vogal átona final é alçada). Além disso, dado que a variante [e] em posição átona final, ainda que não seja a variante falada na variedade de Rio Grande/RS, é encontrada em outros dialetos do PB, caberia aos aprendizes apenas adaptar seu sistema de forma a produzir nesta posição silábica a vogal [e], conforme os padrões acústico-articulatórios da L2.

H2: haverá uma diferença nos valores de F1 (altura da língua) e F2 (anterioridade/posterioridade) no caso de as palavras nas duas línguas não serem cognatas.

Motivação: ainda que se trate de aprendizes experientes, com, no mínimo, três anos de estudos formais da L2, acredita-se que as palavras cognatas tendem ainda a exercer efeito no que concerne à seleção e ao acesso lexical.

H3: não haverá diferença entre os grupos de aprendizes em relação aos padrões acústicos da L2 (F1 e F2).

Motivação: dada a saliência desse aspecto, bem como o fato de algumas variedades do $\mathrm{PB}$ apresentarem a vogal [e] em posições átonas finais, acredita-se que, desde os primeiros estágios de desenvolvimento linguístico, os aprendizes já produzam a átona final sem alçamento, de modo que não haja distinção entre aprendizes que estudem o idioma há 3 ou há mais de 4 anos. 


\subsection{Participantes}

Este estudo contou com uma amostra de 11 aprendizes (do sexo feminino) de espanhol como L2, moradoras da cidade de Rio Grande (RS, Brasil), estudantes de Letras Português/Espanhol.

No que se refere ao tempo de aprendizado da L2, as mesmas foram divididas em dois grupos: o Grupo A, aquele que relatou três anos de contato com a L2 (somando cinco participantes), e o Grupo B, aquele que relatou entre quatro e seis anos de contato com a L2 (somando seis participantes). Havia, ainda, a intenção de se coletarem dados de aprendizes com menor tempo de estudo do idioma (uma vez que, conforme expresso na seção anterior, esperamos que os aprendizes deixem de alçar a vogal final logo em uma primeira etapa de sua trajetória desenvolvimental), mas, devido à dificuldade de recrutamento de sujeitos, tal meta não foi concretizada. A média de idade para o Grupo A é de 27,6 anos $(\mathrm{DP}=11,6)$ e a média de idade para o Grupo B é de 24,16 anos ( $\mathrm{DP}=3,3$ ).

\subsection{Materiais}

Para a coleta de dados, utilizamos duas tarefas de leitura (de frase-veículo), sendo uma em português e outra em espanhol. Todos os estímulos utilizados no instrumento de coleta foram inseridos em contextos vozeados antecedentes e precedentes, já que alguns estudos apontam que tais contextos, quando surdos, podem contribuir para um desvozeamento de tal vogal (cf. MENEZES, 2012).

Além disso, procuramos controlar a frequência de ocorrência na língua dos estímulos, para que em todas as condições das tarefas de leitura (português/espanhol, cognato/não cognato), tanto intra-língua como entre-línguas, houvesse uma igualdade estatística neste requisito. Utilizamos os seguintes bancos de dados de frequência: Ugent.be (para as frequências do português e para as frequências do espanhol) ${ }^{6}$ e EsPal - Spanish Lexical Database (que forneceu frequências para as palavras do espanhol que não apareciam no Ugent.be) ${ }^{7}$. O resultado estatístico de uma ANOVA Mista (realizada no programa SPSS, versão 18) mostrou que os estímulos estavam equilibrados, pois a diferença para as frequências entre cognatos e não cognatos, em espanhol, não foi significativa, $F(8)=4,609, p>.05$, assim como a diferença entre cognatos e não cognatos em português, $F(8)=6,756, p>.05$. Também a diferença entre cognatos e não-cognatos entre as línguas não foi significativa, $\mathrm{F}(8)=4,197, \mathrm{p}>.05$. 
Ao final, selecionamos vinte estímulos, sendo cinco cognatos (português: sede, mude, vende, grande e ronde; espanhol: sede, mude, vende, grande e ronde) e cinco não cognatos (português: fede, rude, vinde, sande e bonde; espanhol: quede, hunde, dude, monde e rinde) em cada língua. Além dos estímulos para a análise, foram acrescentados quatro estímulos distratores em cada língua, sendo dois cognatos (português: roce e $c a-$ sasse; espanhol: roce e casase) e dois não-cognatos (português: coce e vazasse; espanhol: broce e dañase).

Estabelecemos como frase veículo Digo X bien. para o espanhol, e Digo $X$ bem, para o português, sendo a letra $X$ relativa aos estímulos. Além disso, utilizamos o site randomizer.org para gerar quatro conjuntos de ordens randômicas. Assim, para que fossem garantidos diferentes ordenamentos de apresentação dos itens lexicais nas frases-veículo, foram construídos quatro conjuntos de slides diferentes (no programa Power Point), cada um contendo as catorze frases-veículo a serem lidas pelas participantes.

\subsection{Procedimentos de coleta e análise de dados}

As participantes assinaram o Termo de Consentimento antes de iniciarem as tarefas de leitura. Ressaltamos que a coleta de dados foi realizada individualmente. Utilizamos o software Audacity, um Headset Microsoft 3.000 e um notebook Positivo Intel Inside para a realização das gravações das tarefas de leitura.

A ordem das tarefas de leitura (português e espanhol) foi intercalada, de forma que metade da amostra realizou primeiro a tarefa em L1 e depois em L2, e o restante da amostra realizou primeiro a tarefa em L2 e depois em L1. Além disso, as instruções foram dadas na língua da tarefa e o intervalo de tempo entre a leitura de um instrumento e outro não era superior a 5 minutos $^{8}$. Quando a informante terminava as tarefas de leitura, a pesquisadora a convidava a preencher o questionário histórico-linguístico. Assim, cada sessão durou por volta de vinte minutos. A análise acústica dos dados foi feita no software Praat, versão 6.0.05 (BOERSMA; WEENINK, 2015). Essa medição foi realizada manualmente para cada vogal átona final /e/ da amostra de dados, através do método LPC (Linear Predictive Coding). 


\section{Descrição e análise dos resultados}

Esta seção será organizada em três partes distintas. Primeiramente, descrevemos e discutimos os dados referentes aos valores de F1 e F2 (H1). Logo, detalhamos os resultados referentes à variável status cognato (H2). Por último, apresentamos os resultados referentes à variável tempo de estudo da L2 (H3).

\subsection{Padrões acústicos}

Na Tabela 1, mencionamos as médias (em Hertz) dos eixos relativos à altura (F1) e à anterioridade/posterioridade da língua (F2) de ambos os grupos de aprendizes de espanhol.

Tabela 1: Valores referentes às médias, desvios-padrão e coeficientes de variação (CVs) para os valores de F1 e F2 (em Hertz) da vogal /e/ final (Em espanhol e português).

\begin{tabular}{c|c|c|c|c|c|c|c|c} 
Grupo & $\begin{array}{c}\text { E.C. } \\
\text { F1 }\end{array}$ & $\begin{array}{c}\text { E.C. } \\
\text { F2 }\end{array}$ & $\begin{array}{c}\text { E.N.C. } \\
\text { F1 }\end{array}$ & $\begin{array}{c}\text { E.N.C. } \\
\text { F2 }\end{array}$ & $\begin{array}{c}\text { P.C. } \\
\text { F1 }\end{array}$ & $\begin{array}{c}\text { P.C. } \\
\text { F2 }\end{array}$ & $\begin{array}{c}\text { P.N.C. } \\
\text { F1 }\end{array}$ & $\begin{array}{c}\text { P.N.C. } \\
\text { F2 }\end{array}$ \\
\hline $\mathrm{A}$ & 453,30 & 2189,38 & 452,67 & 2187,61 & 408,06 & 2071,63 & 388,12 & 2054,89 \\
& $(16,03)$ & $(49,86)$ & $(21,31)$ & $(54)$ & $(46,15)$ & $(96,04)$ & $(32,79)$ & $(122,61)$ \\
\hline & $\mathrm{CV}=3,53$ & $\mathrm{CV}=2,27$ & $\mathrm{CV}=4,70$ & $\mathrm{CV}=2,46$ & $\mathrm{CV}=11,30$ & $\mathrm{CV}=4,63$ & $\mathrm{CV}=8,44$ & $\mathrm{CV}=5,96$ \\
\hline $\mathrm{B}$ & 443,61 & 2184,31 & 451,24 & 2245,34 & 395,11 & 2113,55 & 395,12 & 2047,46 \\
& $(48,80)$ & $(108,68)$ & $(54,90)$ & $(89,38)$ & $(37,71)$ & $(127,08)$ & $(41,56)$ & $(121,11)$ \\
& & & & & & & & \\
\hline & $\mathrm{CV}=11$ & $\mathrm{CV}=4,97$ & $\mathrm{CV}=12,16$ & $\mathrm{CV}=3,98$ & $\mathrm{CV}=9,54$ & $\mathrm{CV}=6,01$ & $\mathrm{CV}=10,51$ & $\mathrm{CV}=5,91$ \\
\hline $\mathrm{A} \mathrm{e} \mathrm{B}$ & 448,01 & 2186,62 & 451,89 & 2219,10 & 401 & 2094,49 & 391,94 & 2050,83 \\
& $(36,32)$ & $(83,11)$ & $(41,10)$ & $(77,91)$ & $(40,11)$ & $(110,65)$ & $(36,15)$ & $(115,59)$ \\
\hline & $\mathrm{CV}=8,10$ & $\mathrm{CV}=3,80$ & $\mathrm{CV}=9,09$ & $\mathrm{CV}=3,51$ & $\mathrm{CV}=10$ & $\mathrm{CV}=5,28$ & $\mathrm{CV}=9,22$ & $\mathrm{CV}=5,63$ \\
& & & & & & & & \\
\hline
\end{tabular}

Legenda: Grupo $A=$ Três anos de estudo da $L 2 ;$ Grupo $B=$ Quatro a seis anos de estudo da L2; E.C. $=$ espanhol cognato; E.N.C. = espanhol não-cognato; P.C. = português cognato; P.N.C. = português não-cognato. 0 desvio padrão para a média de cada grupo é apresentado entre parênteses. Nas linhas que seguem a média dos formantes, apresentam-se os coeficientes de variação (CV) em percentagem (\%).

Como é possível observar na Tabela 1, os valores de F1 e F2 no $\mathrm{PB}$, independentemente do status cognato e do grupo de participantes, são bem próximos. Em relação à $\mathrm{F}$ 1, há pouca diferença: o Grupo B, 
inclusive, apresenta praticamente os mesmos valores nas duas condições da variável status cognato $(395,11 \mathrm{~Hz}$ para cognatos e $395,12 \mathrm{~Hz}$ para não cognatos). Por outro lado, os valores de F2 não são tão próximos, principalmente no Grupo B $(2113,55 \mathrm{~Hz}$ para cognatos e $2047,46 \mathrm{~Hz}$ para não cognatos). Entretanto, é interessante notar que ao mesmo tempo em que há um aumento de F2 na condição cognato pelo Grupo A (2054,89 $\mathrm{Hz}$ para não cognato e 2071,63 Hz para cognato), ocorre o mesmo com o Grupo B (2047,46 Hz para não cognato e $2113,55 \mathrm{~Hz}$ para cognato), sendo que o aumento é maior no segundo grupo $(43,92 \mathrm{~Hz})$.

Em relação aos padrões acústicos em língua espanhola, também é possível observar que as médias são bem próximas, independente do status cognato e do grupo. A maior diferença está entre as médias de F2 (não cognato) do Grupo A e do Grupo B $(2187,61$ Hz e 2245,34 Hz, respectivamente).

Além disso, há bastante variabilidade nos dados inter-grupos, tanto em relação às médias como em relação ao desvio padrão. Entretanto, se olharmos para os valores do coeficiente de variação, tal valor indica que os dados variam pouco em relação à média ${ }^{9}$. Conforme o coeficiente de variação das médias, em todas as variáveis (língua, status cognato e grupo), a anterioridade da língua (F2) varia menos em relação à média do que a altura da língua (F1). Para verificarmos a distribuição normal dos dados para a realização de testes estatísticos, foi realizado um teste de Normalidade, no software SPSS (versão 18). Todos os dados passaram nos testes de normalidade (Kolmogorov-Smirnov e Shapiro-Wilk). Assim, consideramos os dados como sendo normalmente distribuídos.

No caso das informantes do presente estudo, nas produções em espanhol, a vogal /e/ final está ligeiramente mais baixa do que na produção em português. Já em relação a F2, na L2 este formante tem valor mais alto do que nas produções em português (L1); isso demonstra que as informantes estão produzindo a vogal /e/ final, em português, menos anteriorizada em relação ao espanhol. Considerando as diferenças acústico-articulatórias da vogal átona final /e/ entre as línguas, tal dado é de extrema relevância. Como a vogal átona final, em PB, é elevada/alçada, esperávamos que a vogal do $\mathrm{PB}$ seria mais anterior, correspondendo, assim, aos padrões acústico-articulatórios de um /i/. Contudo, pelo fato de se tratar de uma vogal átona, é importante mencionar que o processo de atonização pode também centralizar as vogais altas e elevar a vogal baixa, devido à menor duração das vogais átonas (CALLOU, MORAES E LEI- 
TE, 1996; MEIRELLES, 2011). Além disso, levando-se em consideração a concepção de língua adotada neste trabalho, podemos, ainda, olhar para este dado como um indício de interação entre os dois sistemas vocálicos, interação essa que, consequentemente, pode movimentar inclusive o sistema de L1.

Após a realização de uma ANOVA Mista (SPSS, versão 18), obtivemos os resultados apresentados na Tabela 2.

Tabela 2: Resultados da ANOVA Mista

\begin{tabular}{|l|l|l|}
\hline Efeito & $\begin{array}{l}\text { Significân- } \\
\text { cia (valor de } \\
\text { p) F1 }\end{array}$ & $\begin{array}{l}\text { Significância (valor } \\
\text { de p) F2 }\end{array}$ \\
\hline Língua &, 000 &, 013 \\
\hline Língua/Grupo &, 829 &, 916 \\
\hline Status cognato &, 574 &, 686 \\
\hline Status cognato/Grupo &, 234 &, 817 \\
\hline Língua/Status cognato &, 287 &, 102 \\
\hline Grupo &, 852 &, 581 \\
\hline Língua/Status cognato/Grupo &, 635 &, 184 \\
\hline
\end{tabular}

${ }^{\star} \mathrm{O}$ valor de significância de $\mathrm{p}$ considerado nesta pesquisa é $\mathrm{p}<.05$.

Na ANOVA Mista realizada, verificamos um efeito principal de língua no valor de $\mathrm{F} 1(\mathrm{~F}(1,9)=84,98, \mathrm{p}=, 000)$ e no valor de $\mathrm{F} 2(\mathrm{~F}(1,9)=9,59$, $\mathrm{p}=, 013)$, como é possível observar na Tabela 2. Esse resultado indica que as médias para F1 e F2 diferiram em função da língua na qual as participantes da amostra realizavam a tarefa. Dessa forma, H1 é corroborada, porque as aprendizes estão distinguindo a vogal átona final /e/ entre suas duas línguas: em sua trajetória desenvolvimental, as aprendizes já produzem a átona final do espanhol de acordo com os padrões da L2.

\subsection{Status Cognato}

Em uma observação de caráter descritivo dos dados (ver Tabela 1), é possível verificar que, no caso das produções em espanhol, as médias de F1 entre os grupos variaram mais quando a condição era não-cognato. Já as médias de F2 variaram mais quando a condição era a de cognato, 
principalmente se tomadas as médias do Grupo B isolado (grupo esse que possui de quatro a seis anos de estudo da L2). Em relação aos dados da L1, é possível notar, olhando para o Coeficiente de Variação, que há uma maior variação das médias em altura da língua (F1) do que na anterioridade/posterioridade, tanto na condição cognato como na condição não-cognato.

Quanto ao efeito do status cognato, este não foi significativo em $\mathrm{F} 1, \mathrm{~F}(1,9)=, 341, \mathrm{p}>.05$, ou seja, o status cognato e nenhuma de suas interações com as outras variáveis foi um preditor para a altura da vogal /e/ final. Também para os valores de F2, status cognato não apresentou um efeito significativo, $\mathrm{F}(1,9)=, 175, \mathrm{p}>.05$. Portanto, $\mathrm{H} 2$ não foi confirmada. Ainda que seja necessário ampliar a amostra para que possamos prover uma resposta de caráter mais definitivo, parece que, após um dado grau de experiência com a L2, a variável status cognato não tende a exercer um papel decisivo nas produções da vogal final. Estudos futuros, com aprendizes com menos anos de experiência com a L2, poderão demonstrar se tal variável exerce efeitos entre aprendizes de proficiência mais elementares.

\subsection{Tempo de estudo na L2}

Fazendo-se a mesma análise descritiva dos dados, nas produções em português, é possível apontar que em termos de altura da língua (F1), o Grupo A (aquele que possui três anos de estudo da L2) apresentou mais variabilidade nas médias quando a condição era cognato, enquanto que o Grupo B apresentou mais variação quando a condição era não-cognato. Já em termos de anterioridade da língua (F2), ocorreu o inverso, ou seja, o Grupo A variou mais quando a condição era não-cognato, enquanto o F2 do Grupo B variou mais quando a condição era cognato.

Entretanto, conforme a análise estatística, não houve efeito significativo quanto à variável Grupo em termos de altura $(\mathrm{F}(1,9)=, 037$, $\mathrm{p}>, 05)$ e anterioridade/posterioridade $(\mathrm{F}(1,9)=, 327, \mathrm{p}>.05)$. Também nenhuma das interações (status cognato/grupo e língua/grupo), em nenhum dos padrões acústicos (F1 e F2), apresentou efeito significativo (os resultados foram, respectivamente para cada interação, conforme $\mathrm{o}$ parâmetro acústico: $\mathrm{F} 1=\mathrm{F}(1,9)=1,62, \mathrm{p}>.05$ e F2 $=\mathrm{F}(1,9)=0,57$, p $>.05 ; \mathrm{F} 1=\mathrm{F}(1,9)=, 049, \mathrm{p}>.05$ e $\mathrm{F} 2=\mathrm{F}(1,9)=, 012, \mathrm{p}>.05)$, o que mostra que, embora os dois grupos de informantes diferiam em tempo de estudo da L2, na produção da vogal átona /e/ os grupos são equivalentes, confirmando, assim, a terceira hipótese (H3). Tal resultado pode indicar 
que, desde os três anos, as aprendizes já fazem a distinção entre as duas línguas. Dessa forma, possivelmente, o não-alçamento parece ser uma característica que começa a ser aprendida cedo, no processo de aquisição do espanhol como L2.

Se olharmos para os dados acústicos relativos à L2 (médias A e B: $448,01 \mathrm{~Hz}$ e $2186,62 \mathrm{~Hz}$ para cognatos; 451,89 e $2219,10 \mathrm{~Hz}$ para não cognatos), é possível observar que eles se aproximam de alguns valores reportados na literatura (Santos e Rauber, 2014: /e/ F1 de 472 Hz e F2 de 2270 Hz; Pereyron e Alves, 2016: /e/ F1 de 457,2 Hz). Contudo, tampouco eles chegam a valores muito próximos dos nativos, independentemente do tempo de estudo da L2. Esses valores, entretanto, já se mostram suficientes para marcar uma diferença entre uma vogal final [i] e uma [e].

\section{Conclusão}

Muito se tem discutido, nos campos da Linguística Aplicada e da Psicolinguística, a respeito do processo de desenvolvimento fonético-fonológico de uma segunda língua, o que se justifica pelo fato de que tal processo se apresenta, segundo Machry da Silva (2015), como um dos mais salientes desafios a serem enfrentados pelos aprendizes. Neste trabalho, foi encontrado um efeito principal de língua nas produções, o que possibilita dizer que as informantes desta amostra estão produzindo os sons na L1 e na L2, especificamente a vogal átona final/e/, com características próprias de cada língua. Dessa forma, H1 foi corroborada. Tal resultado permite explorar, ainda que incipientemente, a natureza dinâmica das produções vocálicas e do próprio desenvolvimento de uma L2. Isso porque, em alguma etapa do desenvolvimento (anteriormente a três anos de estudo, conforme sugerem nossos dados), as aprendizes já passaram a fazer essa distinção.

Quanto ao status cognato, esse não apresentou um efeito significativo em nenhuma das línguas. Portanto, H2 não foi corroborada. Cabe mencionar, entretanto, que o valor da significância para a interação status cognato/língua foi marginalmente significativo, o que indica que não se pode afirmar que tal interação não exista. Em uma pesquisa futura, que conte com uma amostra maior, o efeito, talvez, seja encontrado. Por ora, sugerimos que o status cognato não exerce mais efeitos nas produções de aprendizes com maior experiência com a L2.

Por fim, a variável referente ao tempo de estudo na L2 também não apresentou efeito nos padrões acústicos da produção da vogal átona 
final /e/, em ambas as línguas. Portanto, os grupos não diferiram, corroborando, assim, H3, elaborada a partir de nossa expectativa de que as vogais finais do espanhol deixam de ser alçadas em estágios iniciais do desenvolvimento na L2.

É importante mencionar algumas limitações deste estudo. Primeiramente, não contamos com um grupo controle, para determinarmos os valores vocálicos em posição átona, produzidos por falantes monolíngues do português brasileiro e do espanhol, com maior precisão acústica. Como segunda limitação, cabe mencionar que não foi realizado um teste de proficiência com as informantes, pois elas foram agrupadas apenas com base em seu tempo de estudo formal da L2. Além disso, o número da amostra foi pequeno, devido ao baixo número de participantes voluntários no momento de coleta de dados.

Num estudo futuro, mostra-se pertinente, ainda, uma verificação mais individualizada das produções de cada aprendiz, para verificar se os resultados apresentados na estatística inferencial condizem com a análise individual, que, conforme aponta Lima Júnior (2016a, 2016b), se mostra de grande importância para a perspectiva de desenvolvimento linguístico à luz da Concepção de Língua como Sistemas Adaptativos Complexos. Cabe mencionar, ainda, a necessidade de uma futura investigação das produções de aprendizes com menor tempo de experiência com a L2, para que possamos verificar em que estágio desenvolvimental a vogal final deixa de ser produzida como [i], bem como se a variável status cognato vem a exercer efeitos nas etapas iniciais do desenvolvimento linguístico.

Por fim, cabe mencionar que este estudo se constitui como um estudo exploratório. Dessa forma, ainda que reconheçamos as suas diversas limitações, acreditamos que o mesmo pode contribuir com pesquisas em andamento sobre desenvolvimento/aquisição de L2 e interação e dinamicidade no falar bilíngue. Também é importante ressaltar o baixo número de estudos da área que associam a discussão sobre o caráter cognato de línguas próximas, tal como o PB e o espanhol, na aquisição de um aspecto fonético-fonológico. Esperamos, dessa forma, que o presente trabalho caracterize uma chamada de atenção para a necessidade de um maior número de investigações sobre o papel das variáveis aqui investigadas. 


\section{THE PRODUCTION OF UNSTRESSED WORD-FINAL /e/ IN BRAZILIAN PORTUGUESE (L1) AND SPANISH (L2) - AN EXPLORATORY STUDY}

ABSTRACT:

This article presents the results of an experiment on the production of Spanish (L2) word-final /e/ by Southern Brazilian learners. We aimed to the test the effects of two variables, i.e., cognate status and L2 experience in a formal teaching context (Group A: three years of study; Group B: between four and six years of study). The production of the final vowels of the target words, inserted in carrier sentences, were analyzed acoustically. The results showed an effect of language, which indicates that Spanish learners distinguish between the unstressed vowel /e/ in Portuguese and Spanish in terms of height and frontness/backness. However, no effect was found for cognate status and L2 experience. These results raise a discussion on the role of the cognate status variable in the oral productions of more experienced learners KEYWORDS: bilingualism; Spanish (L2); cognate status; L2 experience; vowel production.

\section{NOTAS}

${ }^{1}$ Neste artigo, não se faz distinção entre Língua estrangeira (LE) e Segunda Língua (L2).

${ }^{2}$ Média geral entre falantes do sexo feminino e masculino.

${ }^{3}$ Dados referentes a falantes do sexo feminino.

${ }^{4}$ Todos os valores acústicos do espanhol são de falantes do sexo feminino, exceto os dados reportados por Pereyron e Alves (2016), os quais constituem uma média normalizada entre falantes do sexo feminino e do sexo masculino.

${ }^{5}$ Todos estes estudos acústicos da língua espanhola reportam valores de vogais tônicas, dada a escassez de estudos sobre a posição átona.

${ }^{6}$ Para as frequências do português, acessar o link $<$ http://zipf.ugent.be/open-lexi- 
cons/interfaces/pb-subtitles-unigram/ $>$ e para as frequências do espanhol, acessar o link $<$ http://crr.ugent.be/archives/679>.

${ }^{7}$ Disponível em <http://www.bcbl.eu/databases/espal/>.

${ }^{8}$ Temos ciência de que o ideal seria uma língua em cada dia, mas, dada a dificuldade de conseguirmos que as voluntárias retornassem no dia seguinte, optamos por realizar as duas tarefas de leitura no mesmo dia, cuidando em sempre abordá-las na língua da tarefa.

${ }^{9} \mathrm{O}$ coeficiente de variação fornece a variação dos dados obtidos em relação à média, e é calculado dividindo o desvio padrão pela média dos dados, sendo o resultado multiplicado por 100. Assim, o valor obtido será a porcentagem de quanto o dado varia em relação à média.

\section{REFERÊNCIAS}

ALARCOS LLORACH, E. Fonología Española. La Habana: Instituto Cubano del libro, 1975.

AROSON, L. et al. Características acústicas de las vocales del español rioplatense. In: Fonoaudiológica, 2000. V. 46, n. 2. p. 12-20.

BECKNER, C.; et al. Language is a Complex Adaptative System: Position Paper. In: Language Learning, 2009.

BEST, C. T. A direct realist view of cross-language speech perception. In: STRANGE, W. (Ed.). Speech perception and linguistic experience: issues in cross-language research. Timonium: York Press, 1995. p. 171-204.

; TYLER, M. Nonnative and second-language speech perception: commonalities and complementarities. In: BOHN, O. S.; MUNRO, M. J. (Org.). Language experience in second language speech learning: in honor of James Emil Flege. Filadélfia: John Benjamins Publishing Company, 2007. p. 13-34.

BOERSMA, P. A.; WEENINK, D. Praat: doing phonetics by computer. Disponível em <www.praat.org>. Acesso em: 2 set. 2015.

BRISOLARA, L. B.; SEMINO, M. J. I. ¿Cómo pronunciar el Español? La enseñanza de la fonética y la fonología para brasileños: Ejercicios prácticos. Campinas: Pontes Editores, 2014.

BRISOLARA, L. B.; SOLÉ, A. S. A produção das vogais átonas finais do Português por falantes nativos do Espanhol colombiano. In: ALVES, U. K (Org.). Aquisição fonético-fonológica de língua estrangeira - Investigações Rio-Grandenses 
e Argentinas em discussão. Campinas, SP: Pontes Editores, 2016.

BUSCA PALABRA. Disponível em <www.buscapalabra.com/>. Acesso em: 15 set. 2015 .

CALLOU, D.; MORAES, J. A.; LEITE, Y. O vocalismo do Português do Brasil. In: Letras de Hoje, 1996. v. 31, n. 2, p. 27-40.

CALLOU, D.; LEITE, Y. Iniciação à fonética e à fonologia. 10. ed. Rio de Janeiro: Jorge Zahar, 2005.

CAMARA Jr, J. M. Estrutura da língua portuguesa. Petrópolis (RJ): Vozes, 1970.

CHRISTENSEN, L. B. et al. Research methods, design, and analysis. Estados Unidos da América: Pearson Education Limited, 2015.

CONDE, X. F. Introducción a la fonética y fonología del español. In: Ianua, Revista Philologica Romanica, 2001. ISSN 1616-413X

DE BOT, K.; et al. Dynamic Systems Theory as a comprehensive theory of second language development. In: Contemporany Approaches to Second Language Acquisition, 2013.

DICIONÁRIO DE RIMAS. Disponível em <http://dicionario-de-rimas.net/>. Acesso em: 15 set. 2015.

DIJKSTRA, T. et al. Interlingual homograph recognition: Effects of task demands and language intermixing. In: Bilingualism: Language and Cognition, 1998. V. 1, n. 01. p. 51-66.

ESPAL - Spanish Lexical Database. Disponível em <www.bcbl.eu/databases/espal/index.php>. Acesso em 20 set. 2015.

FLEGE, J. E. Second language speech learning: theory, findings, and problems. In: STRANGE, W. (Ed.). Speech perception and linguistic experience: issues in cross-language research. Timonium: York Press, 1995, p. 233-277.

FLEGE, J. E. Assessing constraints on second-language segmental production and perception. In: MEYER, A; SCHILLER, N. (Eds). Phonetics and Phonology in Language Comprehension and Production: Differences and Similarities. Berlim: Mouton de Gruyter, 2003. p. 319-355.

KENT, R. D; READ, C. Análise acústica da fala. Tradução Alexsandro Meireles. $1^{\mathrm{a}}$. ed. São Paulo: Cortez, 2015.

KUPSKE, F. F. Imigração, atrito e complexidade: A produção das oclusivas surdas iniciais do Inglês e do Português por sul-brasileiros residentes em Londres. Rio Grande do Sul: Universidade Federal do Rio Grande do Sul, 2016. Tese (Doutorado em Letras), Universidade Federal do Rio Grande do Sul, 2016. 
LADEFOGED, Peter; JOHNSON, Keith. A course in phonetics. Canadá: Wadsworth Cengage Learning, 2010.

LEMHÖFER, K.; DIJKSTRA, T. Recognizing cognates and interlexical homographs: Effects of code similarity in language specific and generalized lexical decision. Memory \& Cognition, 2004, 32, p. 533-550.

LIMA JR., R. A necessidade de dados individuais e longitudinais para análise do desenvolvimento fonológico de L2 como sistema complexo. In: Revel, 2016. v. 14 , n. 27, p. 203-225a.

Análise longitudinal de vogais do Inglês-L2 de brasileiros: dados preliminares. Gradus - Revista Brasileira de Fonologia de Laboratório, 2016. v. 1, n. 1, p. 146-176b.

LIPSKI, J. M. Español de América. Madrid: Cátedra, 2007.

MACHRY DA SILVA. S. A produção das vogais médias tônicas do Português (L2) por falantes nativos do Espanhol. In: Aquisição Fonético-Fonológica de Segunda Língua/Língua Estrangeira. ORGANON. Porto Alegre: UFRGS, 2015. V. 1, n. 1. p. 91-108 ISSN 0102-6267

MATZENAUER, C. L. B. et al. Vogais em posição postônica final: Percepção e produção (No sul do Brasil). In: Revista da ABRALIN, 2015. V. 14, n. 1. ISSN 2178-7603

MENEZES, F. O. As vogais desvozeadas no Português brasileiro: Investigação acústico-articulatória. Campinas: Universidade Estadual de Campinas, 2012. Dissertação (Mestrado em Linguística), Universidade Estadual de Campinas, 2012.

PEREYRON, L.; ALVES, U. K. A aquisição do sistema vocálico do português por falantes nativos da variedade rio-platense de espanhol: uma discussão sobre a direcionalidade da transferência vocálica. In: Domínios de Linguagem v. 10, n. 2, p. 616-645, 2016.

RANDOMIZER. Disponível em <www.randomizer.org/>. Acesso em: 2 out. 2015. REAL ACADEMIA ESPAÑOLA; ASOCIACIÓN DE ACADEMIAS DE LA LENGUA ESPAÑOLA. Nueva gramática de la lengua española: fonética y fonología. Barcelona: Espasa, 2011.

RIMADOR. Disponível em <www.rimador.net/index-po.php>. Acesso em: 15 set. 2015.

SILVA, R. O. Características acústicas e articulatórias das vogais postônicas na variedade do Português Brasiliense. Brasília: Universidade de Brasília, 2012. Dissertação (Mestrado em Letras), Universidade de Brasília, 2012.

UGENT BE. Disponível em <http://crr.ugent.be/>. Acesso em: 20 set. 2015. 
VIEIRA, M. J. B. Neutralização das vogais médias postônicas. Porto Alegre: UFRGS, 1994. Dissertação (Mestrado em Letras), Universidade Federal do Rio Grande do Sul, 1994.

. As vogais médias postônicas: uma análise variacionista. In: BISOL, L; BRESCANCINI, C. R. (org.). Fonologia e variação: recortes do português brasileiro. Porto Alegre: EDIPUCRS, 2002. p. 127-159.

; SILVA, T. C.. Redução vocálica em postônica finnal. In: Revista da ABRALIN, 2015. V. 14, n. 1. ISSN 2178-7603

Recebido em: 30/04/2017

Aceito em:14/07/2017 